Check for updates

Cite this: RSC Adv., 2019, 9, 39545

Received 3rd September 2019

Accepted 16th November 2019

DOI: 10.1039/c9ra07019b

rsc.li/rsc-advances

\section{Hydrolysis and oxidation of protein and lipids in dry-salted grass carp (Ctenopharyngodon idella) as affected by partial substitution of $\mathrm{NaCl}$ with $\mathrm{KCl}$ and amino acids}

\author{
Xiuyun Guo, ${ }^{\text {ab }}$ Shanan Chen, ${ }^{\text {ab }}$ Jiayue Cao, ${ }^{\text {ab }}$ Jingying Zhou, ${ }^{\text {ab }}$ Yanzheng Chen, ${ }^{\text {ab }}$ \\ Muneer Ahmed Jamali ${ }^{c}$ and Yawei Zhang (iD *ab
}

\begin{abstract}
To obtain healthier meat products with reduced $\mathrm{Na}$ content, the salt substitute containing L-histidine and Llysine was compared with $\mathrm{NaCl}$ in the hydrolysis and oxidation of protein and lipids of dry-salted fish during processing. Compared with $\mathrm{NaCl}$-treated fish (S-F), salt substitute treated fish (SS-F) had a lower $\mathrm{Na}$ content, higher moisture content and lower hardness. Sensory analysis showed that salt substitute didn't affect the acceptability of salted fish. The free fatty acids of SS-F treated fish had a slight tendency toward lipolysis at the end of processing. Additionally, the conjugated diene value, lipoxygenase activity and malondialdehyde value were lower in the ventral and dorsal muscles for the SS-F treatment. Meanwhile, the protein carbonyls and thiol groups were significantly decreased as cathepsin B and L activities and FAA content were increased in the ventral and dorsal muscles for the SS-F treatment. LHistidine and L-lysine accelerated the hydrolysis (inhibit the oxidation) of protein and lipids in dry-salted grass carp, illustrating that L-histidine and L-lysine will be a positive approach to develop healthier meat products.
\end{abstract}

\section{Introduction}

Sodium chloride $(\mathrm{NaCl})$ is generally used in fish processing because it acts as preservative and has several other positive technological properties. ${ }^{1,2}$ Traditional aquatic products with $1.0-11.6 \% \mathrm{NaCl}(\mathrm{w} / \mathrm{w})$ or high sodium content is a well-known characteristic of dry-salted fish products. ${ }^{3,4}$ On the other hand, increased consumption of sodium (Na) is linked with the risk of high blood pressure and the development of some other cardiovascular diseases. ${ }^{5,6}$ Therefore, approaches towards reducing the $\mathrm{NaCl}$ content of salted fish has attracted attention throughout the world.

Salted fish was easy to preserve as well as it has a typical developed flavor due to hydrolysis and oxidation of protein and lipid and the rate of hydrolysis and oxidation of protein and lipid vary according to the composition of salt used during the processing of salted fish. ${ }^{7}$ On one hand, lipid and protein oxidation occurring during the processing is an important factor for quality deterioration, such as deterioration of the texture, nutritional value, discoloration of salted fish. ${ }^{8,9}$ On the

${ }^{a}$ College of Food Science and Technology, National Center of Meat Quality and Safety Control, Nanjing Agricultural University, Nanjing 210095, China. E-mail: zhangyawei@njau.edu.cn

${ }^{b}$ Synergetic Innovation Center of Food Safety and Nutrition, Nanjing, China

'Department of Animal Products Technology, Sindh Agriculture University, Tandojam, Pakistan other hand, lipid and protein hydrolysis affect sensory and nutritional qualities of dry-cured meat. The important factors such as salt type and content affected proteolysis and lipolysis which were important biochemical changes during processing, leading to the development of the desired flavor, texture and color in the dry-cured meat products. ${ }^{10}$ Proteolysis and lipolysis has been attributed to endogenous enzymes. ${ }^{11,12}$

In previous studies, most of the researchers focused on the applications of $\mathrm{KCl}$ combined with $\mathrm{MgCl}_{2}$ or $\mathrm{CaCl}_{2}$ in salted fish. ${ }^{13-15}$ However, magnesium salts and calcium hindered the proper penetration of salt into fish tissues ${ }^{16,17}$ and the availability of $\mathrm{KCl}$ (more than $50 \%$ ) might attenuate the flavor and produce bitterness. ${ }^{12,18}$ Therefore, considerable interest had been focused on the application of amino acids as a salt substitute component for meat products, and it was found that L-arginine or L-lysine (Lys) significantly improved the water holding capacity, $a^{*}$ value and textural properties of pork sausages. ${ }^{19} \mathrm{~A}$ salt substitute containing Lys was also reported to result in good physicochemical properties of surimi gels. ${ }^{20,21}$ In our previous study, the application of L-histidine (His) and Lys as salt substitutes remarkably reduced the TBARS value of dry-cured loin compared to the $\mathrm{NaCl}$ treatment. ${ }^{22}$ However, based on our knowledge, research regarding use of amino acids as salt substitute components in dry-salted fish has not been previously reported.

Therefore, in the present study, grass carp (Ctenopharyngodon idella), a freshwater herbivorous fish that generally found in the 
rivers draining East Asia and was cultured around the globe, ${ }^{23}$ was used for the experiment and salted during processing, and the effect of amino acids (His and Lys) as salt substitute on the hydrolysis and oxidation of protein and lipid in salted fish was studied. As well known, in the dorsal muscle the value of lipids is remarkably lower compared to the ventral muscle in fish, such as gilthead sea bream, rainbow trout and European sea bass. ${ }^{24}$ For that reason, there was a need to study and compare the ventral and dorsal muscles of fish for lipid oxidation and hydrolysis, particularly under low $\mathrm{NaCl}$ circumstances. Moreover, interactions among the components His and Lys might have a role in salty taste of $\mathrm{NaCl}^{25}$ Therefore, the current study was designed to analyze the influence of $\mathrm{NaCl}$ (salt) and Lys and His (salt substitute) on hydrolysis and oxidation of protein and lipid in the ventral and dorsal muscles of dry-salted grass carp (Ctenopharyngodon idella) throughout the processing.

\section{Materials and methods}

\section{Fish sample preparation}

Grass carp (Ctenopharyngodon idella) weighing about $1.5 \pm 0.5 \mathrm{~kg}$ was purchased from the market of Nanjing, China in September 2017. The live fishes for the samples were collected in oxygen aerated water and transported within $20 \mathrm{~min}$ to the laboratory in the College of Food Science and Technology, Nanjing Agricultural University, China. After being kept for $1 \mathrm{~h}$ at ambient temperature, the collected fishes were washed, headed, eviscerated and then drained at $4-10{ }^{\circ} \mathrm{C}$ for $15 \mathrm{~min}$. Three fishes were randomly selected and evaluated as the raw material. Next, the six fishes for each of the other processing steps were divided into a salt-fish (S-F) group and a salt-substitute-fish (SS-F) group, with three fishes in each group. The salt substitute purchased from Rolys Co., Ltd, Nanjing, China contained $51.3 \mathrm{~g} / 100 \mathrm{~g}$ of $\mathrm{KCl}, 39.7 \mathrm{~g} / 100 \mathrm{~g}$ of NaCl, $7 \mathrm{~g} / 100 \mathrm{~g}$ L-lys and $2 \mathrm{~g} / 100 \mathrm{~g}$ L-his. For these two groups, the samples were salted with $4 \% \mathrm{NaCl}$ (S-F) or salt substitute (SS-F) at $4{ }^{\circ} \mathrm{C}$ for $48 \mathrm{~h}$. After salting, samples were dried at $15^{\circ} \mathrm{C}$ for $24 \mathrm{~h}$ at $75 \%$ relative humidity $(\mathrm{RH})$. Then, samples were dried at $22{ }^{\circ} \mathrm{C}$ for $24 \mathrm{~h}$ at $70 \% \mathrm{RH}$ and holding at $22^{\circ} \mathrm{C}$ for $24 \mathrm{~h}$ at $65 \% \mathrm{RH}$; holding at $22{ }^{\circ} \mathrm{C}$ for $24 \mathrm{~h}$ at $65 \% \mathrm{RH}$; samples were dried at $24{ }^{\circ} \mathrm{C}$ for $24 \mathrm{~h}$ at $65 \% \mathrm{RH}$ and holding at $24{ }^{\circ} \mathrm{C}$ for $24 \mathrm{~h}$ at $60 \% \mathrm{RH}$; finally, samples were dried at $26{ }^{\circ} \mathrm{C}$ for $24 \mathrm{~h}$ at $55 \% \mathrm{RH}$ and holding at $26{ }^{\circ} \mathrm{C}$ for $24 \mathrm{~h}$ at $50 \% \mathrm{RH}$. At the 4 processing points (end of 2 days salting, drying-processing 2, 4, and 6 days) the ventral and dorsal muscles of the fishes were trimmed off, skinned and collected to obtain the samples for further use. All the sampled muscles were packed using vacuum and kept at $-20{ }^{\circ} \mathrm{C}$ before use.

\section{Physicochemical characteristics}

The potassium and sodium content of the samples were analyzed as described by Zhang. ${ }^{22} \mathrm{HCl}(0.3 \mathrm{M})$ was used to prepare a solution using deionized distilled water to wash the glassware for overnight before use. The moisture content was determined using oven (ISO Norm R-1442, 1979) drying method at $100{ }^{\circ} \mathrm{C}$ until constant weight. Extraction of total lipids was performed by homogenization of minced muscle $(5 \mathrm{~g})$ in $30 \mathrm{ml}$ of chloroform/methanol $(2: 1, \mathrm{v} / \mathrm{v})$ as reported by Folch. ${ }^{26}$ All the analysis was performed in triplicate.

The color of the samples was determined according to the methods described by Cui. ${ }^{27}$ The samples were measured on a freshly cut upper surface of dry-cured beef using a CR-400 colorimeter (Minolta, Osaka, Japan). Before each series of measurements, the instrument was calibrated using a white ceramic tile. Color of the surface was acquired and measured three times for each sample to arrive at the final averaged value. The values are expressed and represented as lightness $\left(L^{*}\right)$, redness $\left(a^{*}\right)$ and yellowness $\left(b^{*}\right)$.

Texture profile analysis (TPA) was carried out by compression to $30 \%$ with a compression probe (P50) of $19.85 \mathrm{~cm}^{2}$ surface contact using a texture analyser TAXT2i (Stable Micro Systems, Godalming, UK). Other parameters were as follows: pre-test speed, $1.0 \mathrm{~mm} \mathrm{~s}^{-1}$; post-test speed, $1.0 \mathrm{~mm} \mathrm{~s}^{-1}$; time between two compressions, $5.0 \mathrm{~s}$. Hardness (N), springiness $(\mathrm{mm})$, chewiness $(\mathrm{mJ})$ and cohesiveness $(\mathrm{N})$ were recorded.

\section{Sensory analysis}

The samples were steamed with the boiled water for $15 \mathrm{~min}$ before they were subjected to sensory analysis to determine the influence of the salt substitution on sensory properties. A panel was conducted with thirty panellists selected from the National Center of Meat Quality and Safety Control of China. The panellists were trained according to the methodology proposed by ISO regulations (ISO 8586:2012) during two weeks with the attributes and the scale to be used. Quantitative descriptive analyse ${ }^{28}$ were carried out to assess the intensity color, saltiness, umami, off-flavor and overall acceptability of the finished product. The samples were presented to the panelists with three-digit codes and in random order. The intensity of every attribute was expressed on an unstructured scale from 0 (sensation not perceived) to 10 (maximum of the sensation). During sensory evaluation, the panellists were situated in private cabinet illuminated with red light. Water to clean the palates and remove residual flavors was used at the beginning of the session and in between samples. The final scores were averaged over all panelists.

\section{Lipases activities assay}

The total lipase activity was carried out using a Total Lipase Test kit (A054-2, Nanjing Jiancheng Bioengineering Co Ltd.). The activities of neutral lipase and acid lipase were determined using the previously documented method by Vestergaard. ${ }^{29}$ The activity of phospholipase was analyzed as reported by Toldrá. ${ }^{30}$ The activities of enzymes were presented as nmol of released 4methylumbelliferone per $\mathrm{h}$ per $\mathrm{g}$ protein. The analysis was performed in triplicate.

\section{Analysis of total lipids and free fatty acids}

Total lipids were extracted from $5 \mathrm{~g}$ of minced muscles according to the method described by Folch, Lees, and SloaneStanley ${ }^{26}$ using $25 \mathrm{ml}$ of chloroform : methanol (2:1) as the solvent. The extracted lipid was expressed as $\mathrm{mg} \mathrm{g}^{-1}$ dry matter. One hundred milligrams of the dry extracted lipids was 
separated using $\mathrm{NH}_{2}$-aminopropyl minicolumns, following the method of Kaluzny, Duncan, Merritt, and Epps. ${ }^{31}$ Free fatty acids (FFAs) were eluted with $3.0 \mathrm{ml}$ of diethyl ether: acetic acid $2 \%$. The amounts of FFAs was expressed as $\mathrm{mg} \mathrm{g}^{-1}$ total lipids. Fatty acids composition was analyzed using gas-liquid chromatography. Gas chromatograph (Trace GC Ultra, Thermo Electron Corporation, Waltham, USA) was used to analyze the methyl esters of fatty acids as reported by Morrison and Smith. ${ }^{32}$

\section{Measurement of conjugated diene}

The conjugated diene and carbonyl value were analyzed using the procedure reported by Coutron-Gambotti and Gandemer ${ }^{33}$ with slight modifications. Lipid sample $(10 \mathrm{mg})$ was mixed with $8 \mathrm{ml}$ of cyclohexane and the absorbance was read at 215 and $232 \mathrm{~nm}$. Finally, the absorbance at $232 \mathrm{~nm}$ was divided with the absorbance taken at $215 \mathrm{~nm}$ to calculate the conjugated diene. All the samples were analyzed in triplicate.

\section{Lipoxygenase (LOX) activity determination}

The LOX activity was determined using a LOX ELISA kit (Jiancheng, Nanjing, China). Minced sample (2 gm) was homogenized on ice using $18 \mathrm{ml}$ of PBS ( $\mathrm{pH}=7.4,0.01 \mathrm{M})$. Thereafter, homogenate was centrifuged $(5000 \mathrm{~g}$, for $10 \mathrm{~min})$ at $4{ }^{\circ} \mathrm{C}$ to get the supernatant. Fifty microliters of sample or standard was poured into the wells; afterward, $100 \mu \mathrm{l}$ of enzyme was added to conjugate to sample wells and standard wells excluding the blank well. The wells were roofed with an adhesive strip and incubated at $37{ }^{\circ} \mathrm{C}$ for $60 \mathrm{~min}$. Next, substrate A and B $(50 \mu \mathrm{l})$ were added to each well, after careful mixing incubated for $15 \mathrm{~min}$ at $37^{\circ} \mathrm{C}$. Lastly, in each well stop solution (50 $\mu$ l) was added and the activity of LOX was measured at $450 \mathrm{~nm}$. Triplicate analysis was performed for the samples.

\section{Measurement of TBARS}

The TBARS value in the samples was analyzed using the procedure reported by Salih, Smith, Price, and Dawson ${ }^{34}$ and the value was presented as $\mathrm{mg}$ of malondialdehyde (MDA) per $\mathrm{kg}$ of muscle. Triplicate analysis was performed for the samples.

\section{Protein carbonyl measurements}

Protein oxidation, as measured by the total carbonyl content, was evaluated by derivatisation with DNPH according to the method described by Ollilainen. ${ }^{35}$ Samples were thawed, minced and then homogenized $1: 10(\mathrm{w} / \mathrm{v})$ in pyrophosphate buffer (pH 7.4) (PB) consisting of $2 \mathrm{mM} \mathrm{Na}_{4} \mathrm{P}_{2} \mathrm{O}_{7}, 10 \mathrm{mM}$ Trismaleate, $100 \mathrm{mM} \mathrm{KCl}, 2 \mathrm{mM} \mathrm{MgCl}_{2}$ and $2 \mathrm{mM}$ EGTA using an ultraturrax homogenizer for $30 \mathrm{~s}$. The homogenates were divided in two equal aliquots of $0.1 \mathrm{~mL}$. Then, proteins were precipitated in both aliquots by adding $1 \mathrm{~mL}$ of $10 \%$ TCA and centrifuged for $5 \mathrm{~min}$ at $5000 \mathrm{rpm}$. Finally, the supernatants were removed and one pellet was treated with $1 \mathrm{~mL} 2 \mathrm{M} \mathrm{HCl}$ and the other one with an equal volume of $0.2 \%(\mathrm{w} / \mathrm{v}) \mathrm{DNPH}$ in $2 \mathrm{M}$ $\mathrm{HCl}$. Both samples were incubated for $1 \mathrm{~h}$ at room temperature (shaken every $15 \mathrm{~min}$ ). After that, samples were precipitated with $1 \mathrm{~mL}$ of $10 \%$ TCA and washed twice with $1 \mathrm{~mL}$ of $1: 1$ ethanol/ethyl acetate $(\mathrm{v} / \mathrm{v})$, shaken, and centrifuged for $5 \mathrm{~min}$ at $10000 \mathrm{rpm}$. The pellets were then dissolved in $1.5 \mathrm{~mL}$ of $20 \mathrm{mM}$ sodium phosphate buffer $\mathrm{pH} 6.5$ containing $6 \mathrm{M}$ guanidine hydrochloride, stirred and centrifuged for $2 \mathrm{~min}$ at $5000 \mathrm{rpm}$ to remove insoluble fragments. Protein concentration was calculated from absorption at $280 \mathrm{~nm}$ using BSA as standard. The amount of carbonyls was measured at $370 \mathrm{~nm}$ and expressed as nmol of carbonyl per mg of protein using the adsorption coefficient for the protein hydrazones $\left(21.0 \mathrm{mM}^{-1} \mathrm{~cm}^{-1}\right)$.

\section{Sulphydryl (SH) content}

The SH group levels were determined according to the method of $\mathrm{Cui}^{36} 0.5 \mathrm{ml}$ of fish sample homegenate was mixed with $2.5 \mathrm{~mL}$ of Tris-Gly-8 $\mathrm{M}$ urea and $0.02 \mathrm{~mL}$ of $4 \mathrm{mg} \mathrm{mL}{ }^{-1} 5,5^{\prime}$ dithiobis-2,2'-nitrobenzoic acid (DTNB). After incubation at $25^{\circ} \mathrm{C}$ for $30 \mathrm{~min}$, the absorbance at $412 \mathrm{~nm}\left(A_{412}\right)$ was recorded. The $\mathrm{SH}$ group level was calculated by eqn (1).

SH group level ( $\mu \mathrm{mol}$ per $\mathrm{g}$ per fish proteins)

$$
=73.53 A_{412} \times D / C
$$

where $D$ is the dilution coefficient (6.04); $C\left(\mathrm{mg} \mathrm{mL}^{-1}\right)$ is the protein concentration in tested sample.

\section{Assay of enzyme activities}

The extracts containing cathepsin B (CTS B, EC 3.4.22.1) and L (CTS L, EC 3.4.22.15) were obtained from $5 \mathrm{~g}$ samples using the methods described by Armenteros et al. (2012). ${ }^{5}$ The activity of enzyme was measured by fluorometric assays using aminoacyl7-amido-4-methyl coumarin (aa-AMC) (Sigma-Aldrich Co., St. Louis, MO) as fluorescent substrates. Activity levels of cathepsin $\mathrm{B}$ (EC 3.4.22.1) and L (EC 3.4.22.15) are determined at $\mathrm{pH} 6.0$ using $0.05 \mathrm{mM}$ N-CBZ-Arg-Arg-AMC and $0.05 \mathrm{mM}$ N-CBZ-PheArg-AMC, respectively.

\section{Free amino acids (FAA) analysis}

Samples for free amino acid analysis were prepared according to the procedures described by Aro $^{37}$ with some modification. Samples $(5 \mathrm{~g})$ were homogenised for 1 min with $45 \mathrm{ml}$ of distilled water. The homogenate was centrifuged for $20 \mathrm{~min}$ at $10000 \mathrm{~g}$ at $4{ }^{\circ} \mathrm{C}$. The supernatant was filtered through filter paper and the samples were diluted $1: 1$ with $4 \%$ trichloroacetic acid (TCA) to give a final concentration of $2 \%$. They were then incubated at $37^{\circ} \mathrm{C}$ for $30 \mathrm{~min}$. The supernatant was filtered again with filter paper. Thereafter, the solution was ultrafiltered through a Millipore filter having a pore diameter of $0.45 \mu \mathrm{m}$. Samples were analysed using a fully automated amino acid analyser HITACHI L-8900 (Hitachi Ltd., Japan).

\section{Statistical analysis}

Data was tabulated and analysis of variance (ANOVA) was applied. Furthermore, to measure the statistical differences between the groups Duncan's multiple-range test was applied at $P<0.05$ using SAS 8.2 (SAS Institute Inc., Cary, NC, USA). Correlations between variables were determined by correlation 

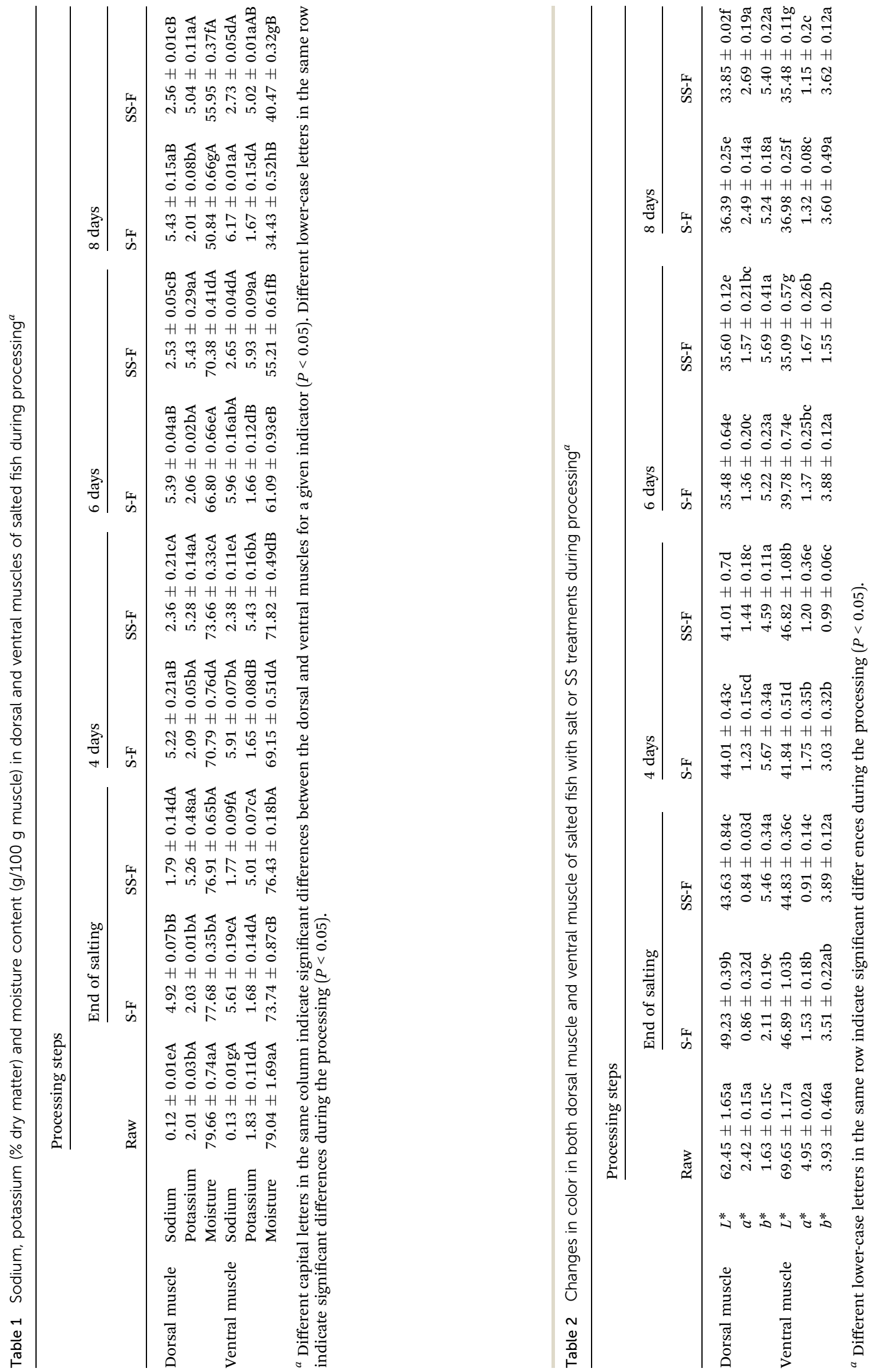
analyses using the Pearson's linear correlation by IBM SPSS Statistics 20 software (IBM, Chicago, IL, USA).

\section{Results and discussion}

\section{Sodium, potassium and moisture contents}

During the processing, in the salt substitute-treated fish (SS-F) the Na content was comparatively $(P<0.05)$ lower than that in the S-F for both ventral and dorsal muscles (Table 1). In the final dorsal muscle, the content of $\mathrm{Na}$ in SS-F was $52.85 \%$ less than that in the S-F group. A similar result was obtained in the ventral muscle and the decrease in Na content was $55.75 \%$. On the contrary, a remarkable $(P<0.05)$ increase in the amount of $\mathrm{K}$ was found in both ventral and dorsal muscles but the $\mathrm{K}$ content was not more than $300 \mathrm{mg} / 100 \mathrm{~g}$ muscle in any sample. According to the dietary reference intakes from the Institute of Medicine, an adequate intake of $\mathrm{K}$ is $4700 \mathrm{mg}$ per day. ${ }^{38}$ If the salt substitute was used to manufacture salted fish and the serving size was $100 \mathrm{~g}$, which indicates that such salted fish product only contributes about one tenth of the $4700 \mathrm{mg}$ per day adequate intake.

The moisture content was decreased with the processing time and it was higher in the dorsal muscle when compared to the ventral muscle and these results are agreed with Testi, ${ }^{39}$ who reported that compared to the ventral muscle the percentage of moisture was higher in the dorsal muscles of rainbow trout, sea bream and sea bass. In our study at the end of drying $8^{\text {th }}$ day, the moisture content was $10.05 \%$ higher in dorsal muscle and $14.92 \%$ higher $(P<0.05)$ in ventral muscle of SS-F group compared to the S-F muscles, respectively. In the Armenteros's ${ }^{5}$ studies, they found that the moisture content of dry-cured ham was not significantly influenced by partial replacement of $\mathrm{NaCl}$ by KCl. Therefore, the higher moisture content might be attributed to the presence of His/Lys. These findings are in agreement with the previous studies. In Zhang's study, ${ }^{\mathbf{4 0}}$ they implied that the presence of His/Lys reduced the cook loss and enhanced the WHC of porcine myosin gels due to exposure of hydrophobic groups of myosin through the electrostatic effect between Lys/His and myosin. In Zhou's ${ }^{19}$ study, they suggested that incorporation of Lys significantly enhance the $\mathrm{pH}$ value of pork sausage resulting in an increase in WHC, which might be due to the formation of complexes with Lys with either $\mathrm{Ca}^{2+}$ or $\mathrm{Mg}^{2+}$ endogenous metallic ions contributing to dissociation of actomyosin. $^{41}$

\section{Color and texture profile analysis}

The evolution of color parameters throughout the processing was shown in Table 2 . At the end of processing, no significant difference $(P>0.05)$ of $a^{*}$ and $b^{*}$ between S-F and SS-F was observed in both dorsal and ventral muscle. Nevertheless, compared with S-F, the $L^{*}$ value of SS-F was decreased by $2.85 \%$ and $1.5 \%$ in dorsal and ventral muscle, respectively. Aliño ${ }^{42,43}$ found that color parameters of dry-cured loins was not affected by the partial replacement of $\mathrm{NaCl}$ by $\mathrm{KCl}$. Therefore, the decrease of $L^{*}$ value might be due to the presence of His/Lys, and this was in agreement with Zhou's ${ }^{19}$ study, who found

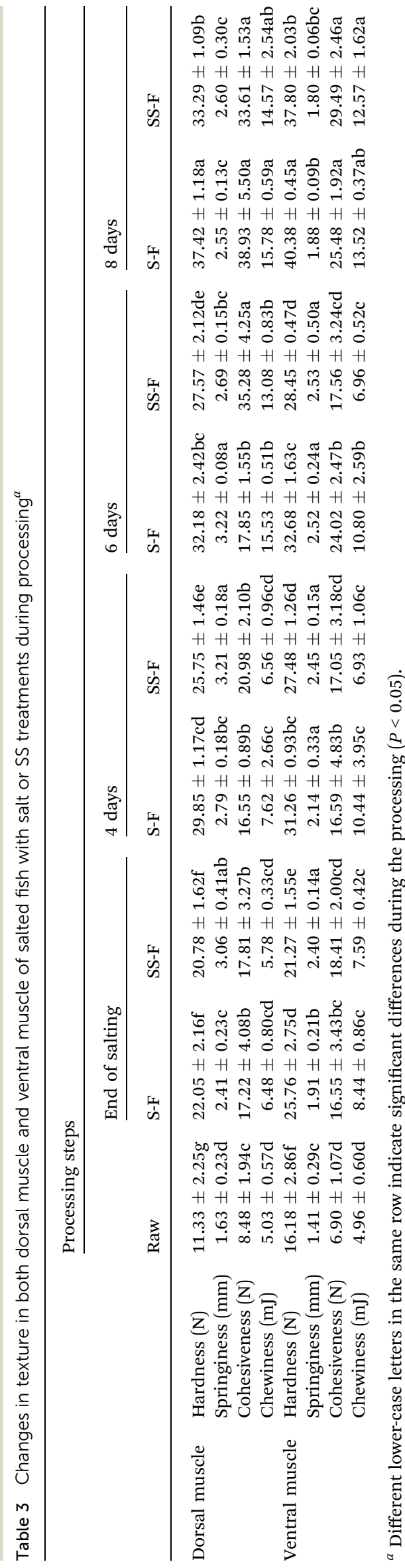


Table 4 The analysis of sensory evaluation in both dorsal and ventral muscle of salted fish with salt or SS treatments ${ }^{a}$

\begin{tabular}{|c|c|c|c|c|}
\hline & \multicolumn{2}{|l|}{ Dorsal muscle } & \multicolumn{2}{|c|}{ Ventral muscle } \\
\hline & S-F & SS-F & S-F & SS-F \\
\hline Saltiness & $7.30 \pm 0.50 \mathrm{a}$ & $6.60 \pm 0.16 \mathrm{a}$ & $6.80 \pm 0.32 \mathrm{a}$ & $6.00 \pm 0.49 a$ \\
\hline Aroma & $7.10 \pm 0.26 a$ & $7.00 \pm 0.15 a$ & $6.50 \pm 0.34 b$ & $7.00 \pm 0.15 a$ \\
\hline Off-flavor & $7.90 \pm 0.88 \mathrm{a}$ & $6.10 \pm 0.37 b$ & $7.20 \pm 0.23 a$ & $5.50 \pm 0.07 b$ \\
\hline
\end{tabular}

${ }^{a}$ Different lower-case letters in the same row indicate significant differences between salt and SS treatments in both dorsal and ventral muscle $(P<$ $0.05)$.

that the incorporation of Lys decreased the $L^{*}$ value of pork sausage. In the previous studies, ${ }^{\mathbf{4 4 , 4 5}}$ it was noted that the loss of water can reduce light scattering, which could lead to loss of transparency, thus increasing the $L^{*}$ value. That is, the increase of moisture content could lead to the decrease of $L^{*}$ value. The negative correlation (Table 11) between moisture content and $L^{*}$ value $(r=-0.995, p<0.01)$ in the present study seemed to support this hypothesis. As shown above, Lys/His caused an increase of moisture content, thus decreasing $L^{*}$ value.

Table 3 showed the mean values for hardness, springiness, cohesiveness and chewiness in both dorsal and ventral muscle. At the end of processing, no significant difference $(P>0.05)$ of springiness, cohesiveness and chewiness between S-F and SS-F was observed in both dorsal and ventral muscle, while a significant decrease $(P<0.05)$ of hardness in SS-F was observed both in dorsal and ventral muscle. Aliñ $0^{42}$ found that the hardness of dry-cured loins was not affected by the $50 \%$ replacement of $\mathrm{NaCl}$ by KCl. Therefore, the decrease of hardness might be due to Lys/His. Texture traits were affected by proteolysis which was due to the effect of enzyme activity changing the protein structures. ${ }^{46}$ The presence of Lys/His increased the activity of cathepsin B and L (shown in Fig. 2), accelerating the hydrolysis of muscle protein, thus resulting in the decreased hardness. In fact, hardness showed a positive correlation with cathepsin B activity $(r=0.899, p<0.05)$. This was in accordance with previous studies, illustrating that the higher activity of cathepsin B was involved in protein degradation which could play a crucial role in the excessive softness defects of dry-cured meat products. ${ }^{5,47}$

\section{Sensory analysis}

Table 4 showed the mean scores for intensity color, saltiness, umami, bitterness and overall acceptability of steamed samples. A significant decrease in intensity color observed in SS-F compared to the S-F could be due to the higher moisture content caused by the presence of Lys/His both in dorsal and ventral muscle (Table 1). No significant differences were observed between S-F and SS-F with respect to saltiness in both dorsal annessd ventral muscle. Regarding saltiness, the assessors didn't notice the different salty taste between S-F and SS-F. This could be due to the fact that salt substitute containing Lys/ His had the similar salty taste with $\mathrm{NaCl}$, since His/Lys might contribute to the salty taste of $\mathrm{NaCl}$ through the interactions. ${ }^{25}$
Notably, a significant decrease in off-flavor was observed in SS-F compared to the S-F both in dorsal and ventral muscle. This could be attribute to Lys/His, since they were flavor enhancers and masker for reducing the sensory defects caused by $\mathrm{NaCl}$ reduction in meat products. ${ }^{\mathbf{1 9 , 2 2 , 4 8 , 4 9}}$ In addition, a significant increase in aroma was observed in SS-F compared to the S-F in ventral muscle. In Armenteros's study, ${ }^{11}$ it was shown that no significant differences were found with respect to aroma between the control (batch I, 100\% NaCl) and batches II and III salted with substitutions up to $50 \%$ of $\mathrm{NaCl}$ by $\mathrm{KCl}$. Therefore, the increase in aroma might be attribute to Lys/His. Lipolysis and oxidation constitute a important group of enzymatic reactions closely related to the final sensory quality, especially aroma of dry cured meat products. There was an initial breakdown of tri-acylglycerols and phospholipids by lipases and phospholipases, respectively, followed by oxidative reactions that produce aroma volatile compounds. ${ }^{50}$ The presence of Lys/ His caused the increase of phospholipase activity, accelerating the hydrolysis of lipid, resulting in the increase of FAA, ultimately producing more aroma volatile compounds through oxidative reactions. The hypothesis was confirmed by correlation analysis (Table 11), where a positive correlation between aroma content and phospholipase activity was shown $(r=0.887, p<0.05)$.

Moreover, there was not significant difference in overall acceptability between S-F and SS-F, indicating that salt substitute containing Lys and His could been used to reduce $\mathrm{NaCl}$ without affecting the products flavor and acceptability.

\section{Comparison of free fatty acids}

In the dorsal muscle, there are no any remarkable variations in the total content of polyunsaturated (PUFA), saturated (SFA) and monounsaturated fatty acids (MUFA) among the S-F and SSF during the entire processing sequence, except SFA and PUFA at the end of 6 days. As shown in Table 5, a marked $(P<0.05)$ increase in the C15:0 and C18:3 content of SS-F was observed at the end of salting. On the $8^{\text {th }}$ day at the end of processing, the C15:0, C17:1, C18:3 and C20:3n3 content in SS-F was comparatively $(P<0.05)$ higher than that in S-F, indicating a trend toward lipolysis in SS-F. The increase of SFA (C15:0) might be due to the application of His in the salt substitute because His and iron ions constitute the catalytic center of the fatty acid desaturases, which were enzymes that could catalyze substrate 


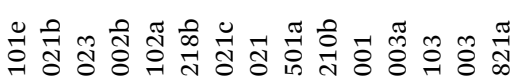
$\mathrm{H} H+\mathrm{H} H+\mathrm{H} H+\mathrm{H} H+H+H+$

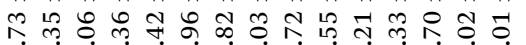
○े

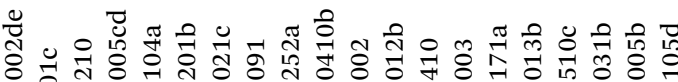

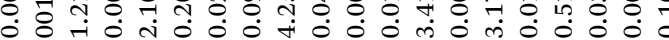
$H+H+H+H+H+H+H+H+H+H+H+H+H+H$

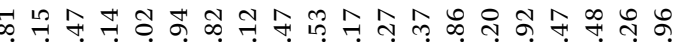

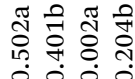

H H H H

뇽

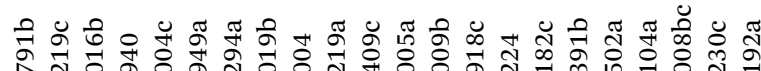
众 $H+H+H+H+H+H+H H+H+H+H+H+H+H+H+$

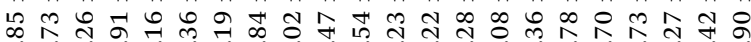
बं००

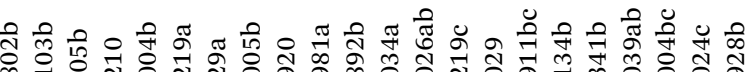

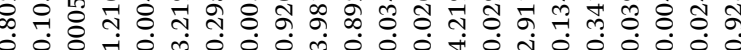
$H+H+H+H+H+H+H+H+H+H+H+H+H+H+H ~ H$

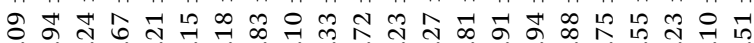
$\dot{0}$ 迥

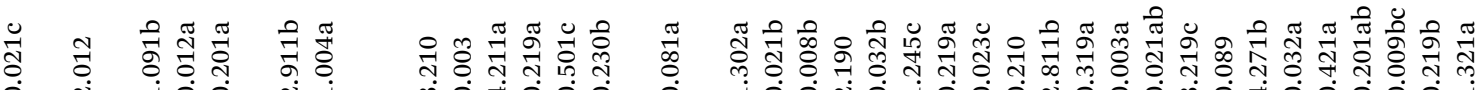

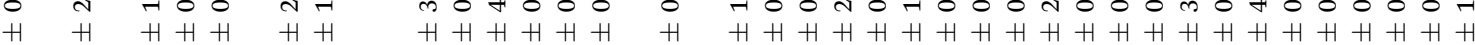
ப艹

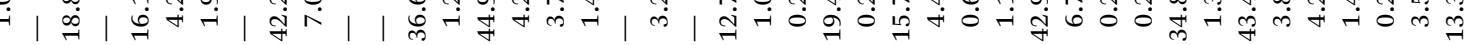

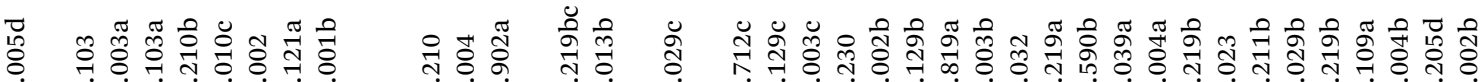

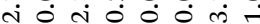

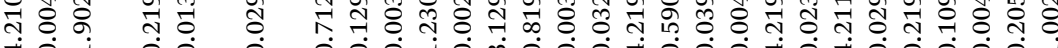

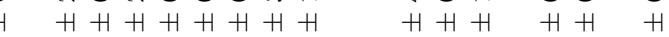
|

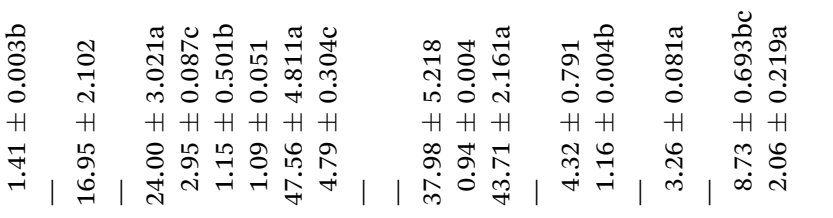

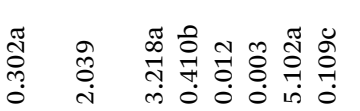

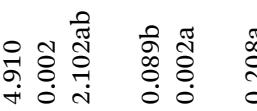
$\begin{array}{llllll}H & H\end{array}$ H H H H H H H H 完,

\section{至}

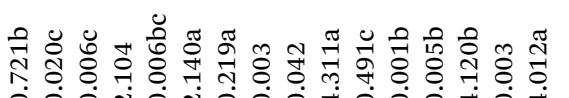
0
$H$ 央陉

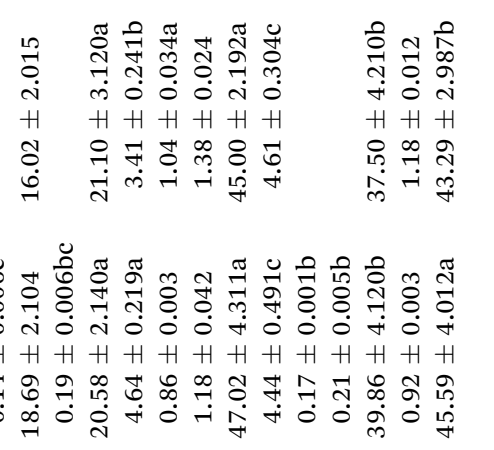

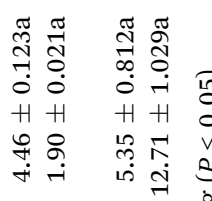

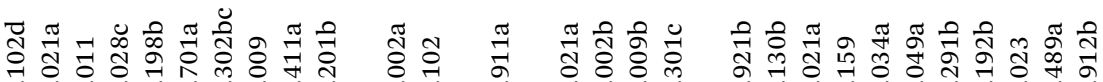

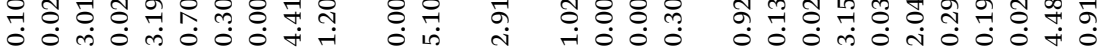

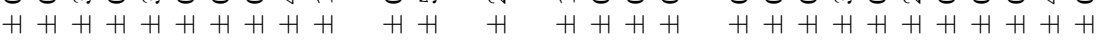

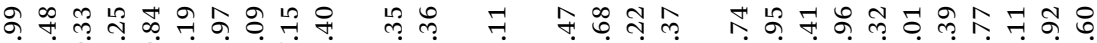

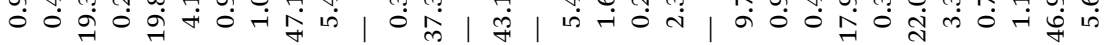

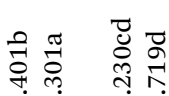
०. H H H H :뉴 $\stackrel{\infty}{\circ}$ ले

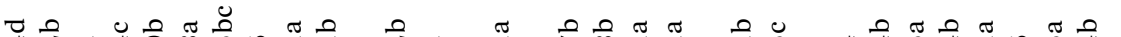

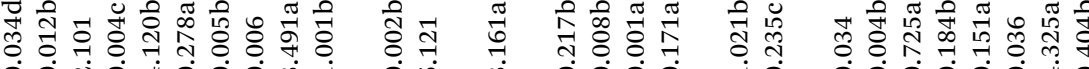

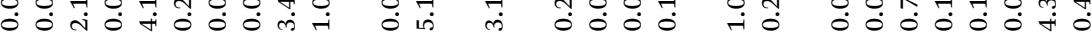

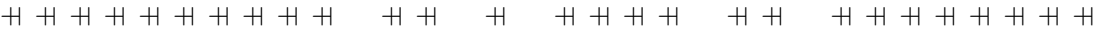
๙ூ ơ

岇颛

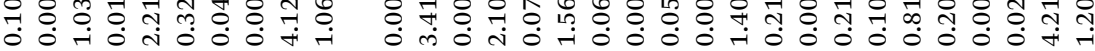

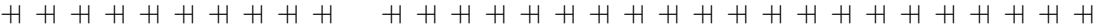

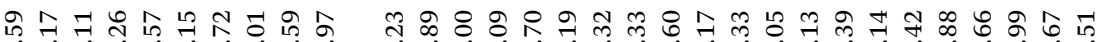

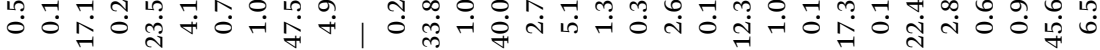

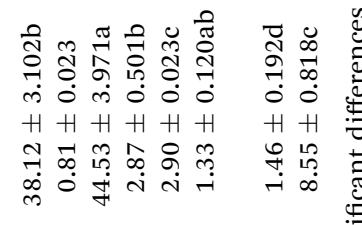

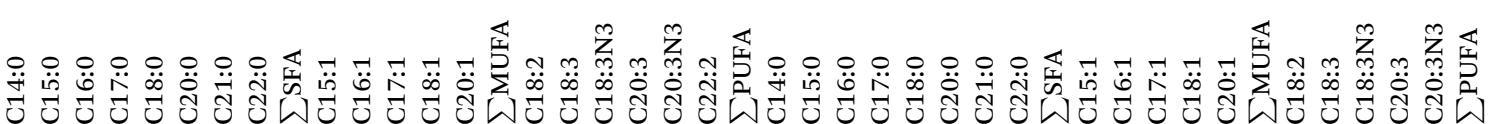
范 

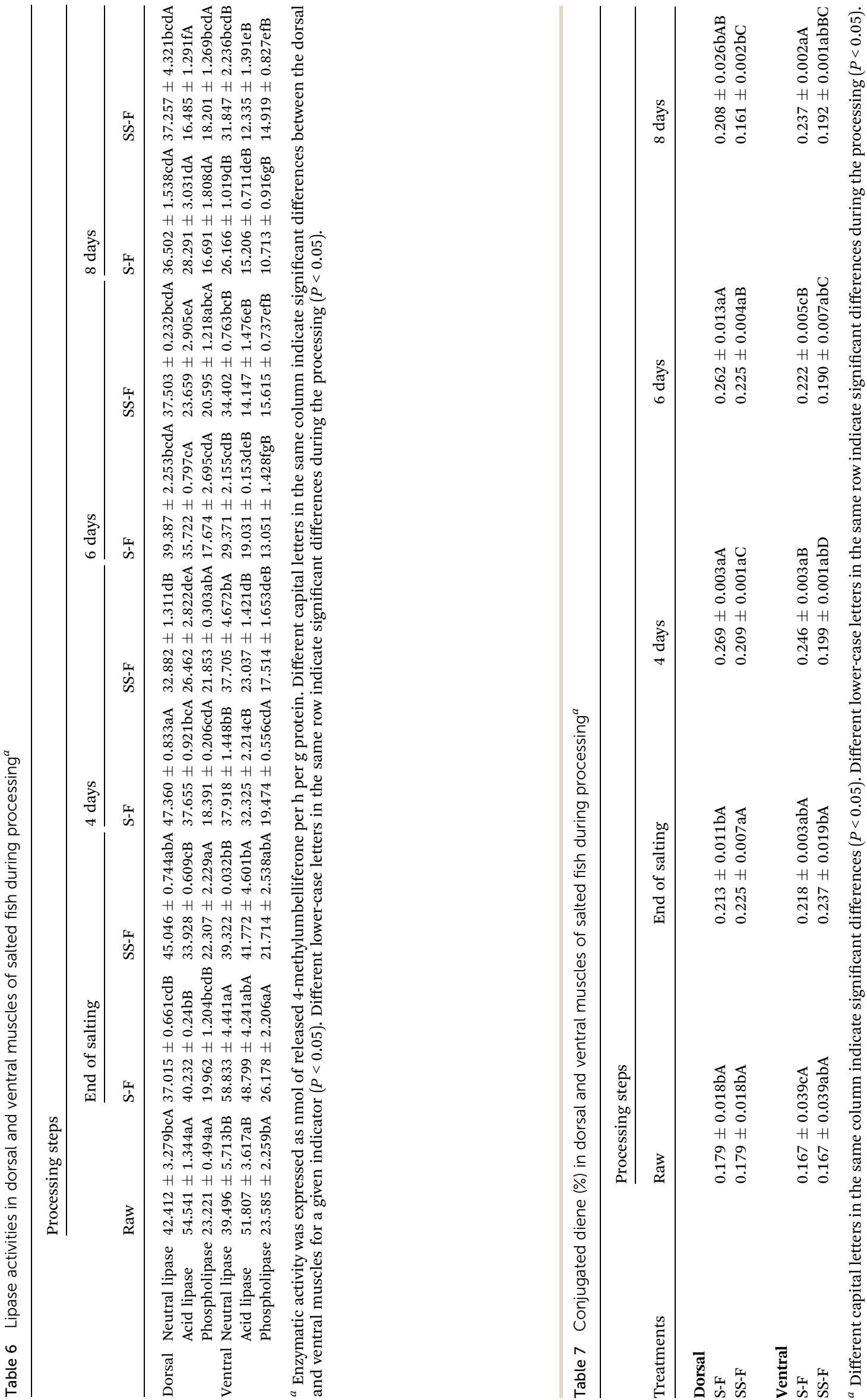


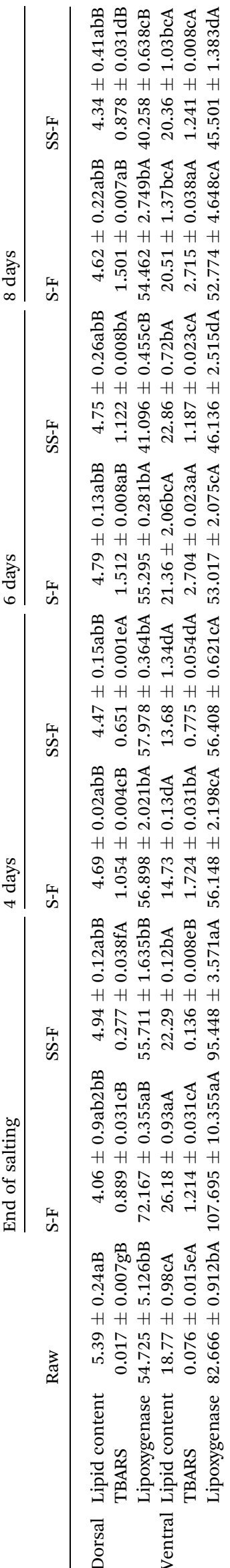

SFA to synthesize UFA. ${ }^{51}$ Hence, it is suggested that the adding of histidine might cause a competitive binding to iron ions at the catalytic center, leading to a reduction in fatty acid desaturase activity, inhibiting the catalytic reaction, resulting in the increase of SFA. In parallel, the increase of MUFA (C17:1) and PUFA (C18:3 and C20:3n3) might be due to the increase of phospholipase activity (shown in the following analysis of lipase activities) caused by His/Lys, while a positve correlation between PUFA and phospholipase activity $(r=0.892, p<0.05)$ was shown in Table 11.

In the ventral muscle, the content of C14:0 and C15:1 in SS-F was higher than that in S-F on the $6^{\text {th }}$ day, while a remarkable $(P<0.05)$ decrease was noticed in the final product. Among the PUFA, the C18:2, C18:3 and C20:3n 3 contents in SS-F were significantly $(P<0.05)$ higher when compared to the S-F at the end of 6 days. During the entire process, the SS-F treatment had a remarkably higher content of total PUFA compared to the S-F $(P<0.05)$. PUFA is more susceptible to oxidative damage than MUFA and SFA, ${ }^{52}$ and the high PUFA content of ventral muscle in dry-salted fish makes it susceptible to oxidative degradation.

\section{Lipase activities between SS-F and S-F}

Among the various types of lipolytic enzyme activities, highest activity was seen in neutral lipase during the processing from the 4 to 8 days of drying (Table 6). These results are in agreement with the findings of Zhou and Zhao, ${ }^{53}$ who previously reported the highest activity of neutral lipase in Jinhua ham. In dorsal muscle, no significant difference in neutral lipase activity was found between SS-F and S-F from 6 to 8 days, while a remarkably $(P<0.05)$ lower activity of acid lipase was found in SS-F compared to S-F. These findings are matched with the Zhang, ${ }^{22}$ who reported that the acid lipase in dry-cured loin was obviously inhibited by $0.05-0.4 \mathrm{M} \mathrm{NaC} / \mathrm{KCl}$ and $0.05-0.25 \mathrm{M}$ Lys. In the salt substitute of the present study, the $\mathrm{NaCl}$ and $\mathrm{KCl}$ content was up to $91 \%$. Therefore, $\mathrm{NaCl}$ and $\mathrm{KCl}$ seemed to contribute a great inhibition in acid lipase effect. In parallel, the activity of phospholipase in SS-F was higher than S-F from beginning to 6 days, while no significant difference was found at the end of processing. In the Zhang' ${ }^{22}$ studies, they found that the phospholipase of dry-cured loin was not significantly influenced by partial replacement of $\mathrm{NaCl}$ by $\mathrm{KCl}$, and the activity of phospholipase was increased in the presence of Lys/ His. Therefore, the higher phospholipase activity was attributed to the presence of His/Lys. The results was in accordance with Liu's studies, ${ }^{54}$ who found that the phospholipase activity in dry cured beef was increased when treated with salt substitute containing Lys and His. This increased phospholipase activity in SS-F during the processing might be responsible for the increase of free fatty acid content described above.

In the ventral muscle, no significant difference in neutral lipase activity and acid lipase activity was found between SS-F and S-F, while the activity of phospholipase in the final SS-F was $39.26 \%$ higher than S-F $(P<0.05)$. Accordingly, a significant higher total PUFA content in SS-F was found as shown in Table 5. Kaneniwa ${ }^{55}$ found that the increase in free fatty acids was attributed to the hydrolysis of phospholipids in silver carp 
and noted that lipid hydrolysis was principally under the control of phospholipase. It is known that His is part of the active center of phospholipase in lysosomes ${ }^{56}$ and that higher phospholipase activity in porcine loin was obtained for 0.20.4 M Lys and 0.05-0.4 M His. ${ }^{22}$ Accordingly, our results shows that the application of His and Lys may affect the activity of lipase catalytic in dry-salted fish.

\section{Conjugated diene comparisons}

Amount of conjugated diene was significantly $(P<0.05)$ decreased in SS-F group compared to the S-F in both dorsal and ventral muscles from 4 to 8 days of drying (Table 7 ). At the end of processing, the conjugated diene value in SS-F was $22.59 \%$ less than that in S-F for the dorsal muscle $(P<0.05)$. A similar phenomenon was found in the ventral muscle. It is generally accepted that PUFAs are particularly susceptible to hydrogen abstraction by free radical attack, becoming free radical intermediates themselves, which results in the arrangement of the double bond to conjugated dienes. ${ }^{57}$ Refsgaard $^{58}$ also reported that the amino group of lysine can react with lipid free radicals or lipid peroxidation endproducts. Therefore, it is suggested that in the present study the applications of Lys as salt substitute may decrease the chain reactions of reactive lipid free radicals. Moreover, in the final product, no considerable $(P>0.05)$ difference in conjugated diene was observed in SS-F or S-F between the ventral and dorsal muscle.

\section{Lipid oxidation}

In the both muscles dorsal and ventral, no statistically $(P>0.05)$ variation was found in the amount of lipid among S-F and SS-F during processing (Table 8). In the ventral muscle, the amount of lipid was apparently higher than that in the dorsal muscle and the ventral muscle was more susceptible to oxidative damage due to its higher amount of polyunsaturated fatty acid. ${ }^{59}$ In our study, the TBARS value of the all samples of SS-F was remarkably $(P<0.05)$ lower than those of S-F throughout the processing. In the final SS-F product, the TBARS value was $41.51 \%$ and $54.29 \%$ less than that in the S-F product for dorsal muscle and ventral muscle, respectively. This might be due to the introduction of histidine into the salt substitute. Similarly, $\mathrm{Zhai}^{\mathbf{6 0}}$ reported that the histidine, as a single oxygen scavenger, remarkably reduce the formation of MDA content and decrease the lipid peroxidation in myocardial membranes of rat.

Lipoxygenase (LOX) was a non-heme ion containing dioxygenase that specially catalyzes the oxygenation of polyunsaturated fatty acids (PUFA) containing a cis, cis-1,4-pentadiene moiety $\left(-\mathrm{CH}=\mathrm{CH}-\mathrm{CH}_{2}-\mathrm{CH}=\mathrm{CH}-\right)$ to produce conjugated unsaturated fatty acid hydroperoxides. ${ }^{61}$ Therefore, there was a negative correlation between PUFA content and LOX activity, which was confirm by the correlation analysis $(r=-0.888, p<0.05)$ in the present study (Table 11). As shown in Wang's study, ${ }^{62}$ the decrease of total free fatty acid as flavour precursors at the marinating stage may result from the promotion of oxidation by increasing LOX activity. LOX catalyzed the incorporation of dioxygen molecules into polyunsaturated fatty acid and was responsible for the initial 
post-mortem production of hydroperoxides in fish. ${ }^{63}$ After the end of 6 days of processing, SS-F presented a significant $(P<0.05)$ decrease in LOX activity compared with S-F in ventral muscle and dorsal muscle (Table 8). At the end of processing, the LOX activity in SS-F was $26.08 \%$ and $13.78 \%$ less than that in S-F for dorsal muscle and ventral muscle, respectively. Ling $^{64}$ stated that the availability of lysine caused higher inhibitory effect of paederosidic acid on the LOX activity, furthermore, the LOX activity inhibition was shown only with the presence of lysine in the case of mixtures of gardenogenins $\mathrm{A}$ and $\mathrm{B}$. Consequently, it is

(a)
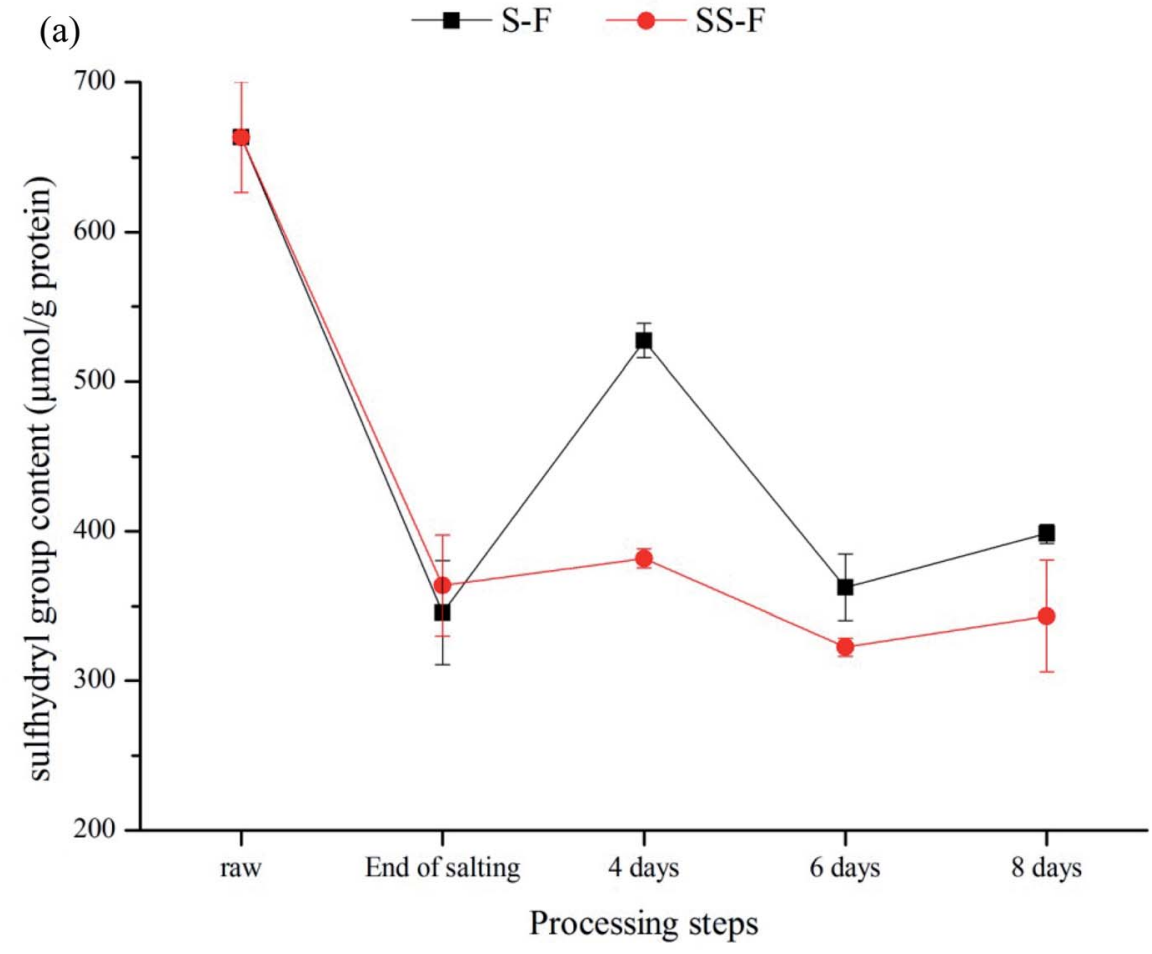

(b)
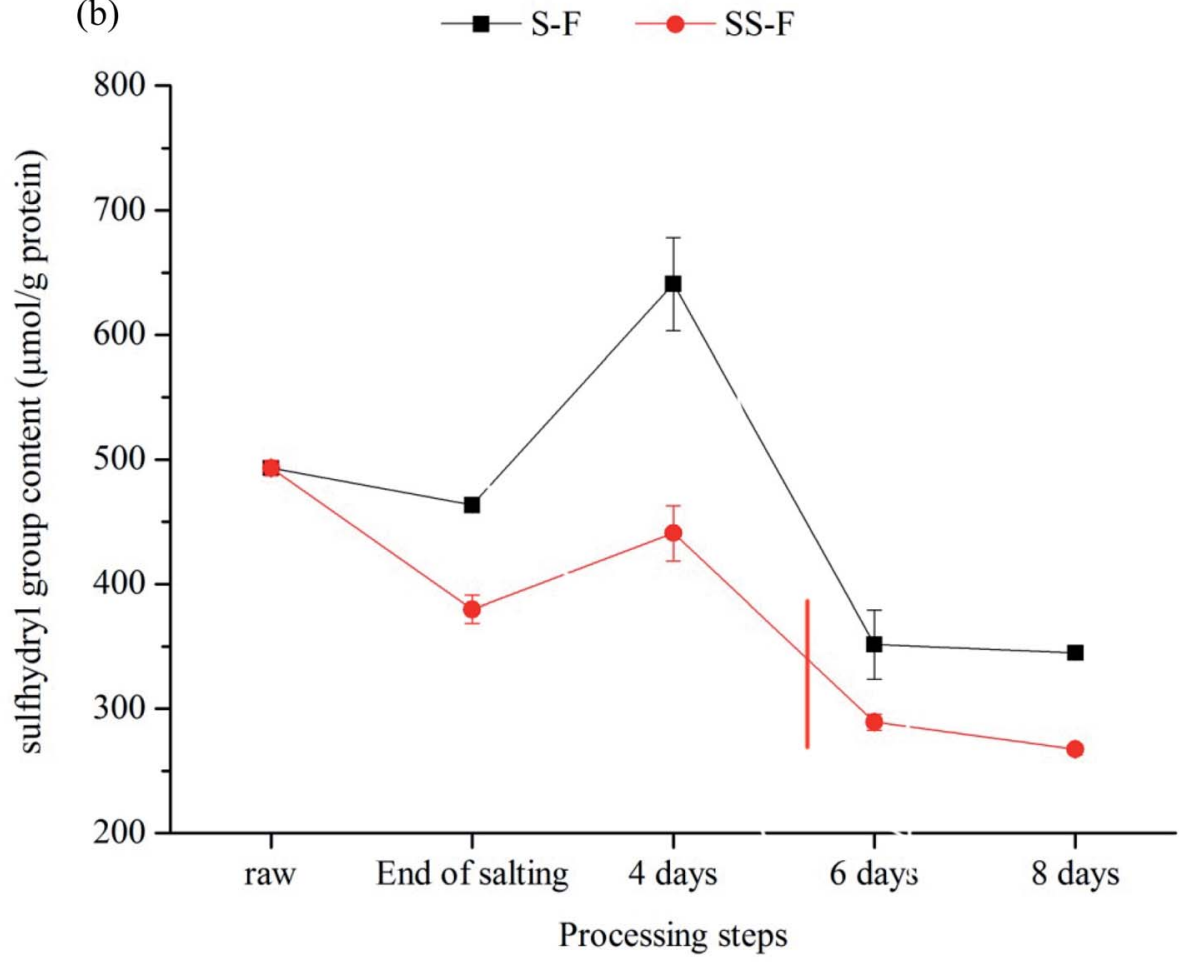

Fig. 1 Changes in sulfhydryl group content in dorsal (a) and ventral muscles (b) of salted fish with salt or SS treatments during processing. 
suggested that the lysine in the salt substitute have a role in the inhibition of LOX activity in dry-salted fish.

\section{Protein carbonyl measurements}

The carbonyl contents in dorsal and ventral muscles of salted fish during processing were shown in Table 9. The amount of carbonyl groups significantly increased $(p<0.05)$ in both dorsal and ventral muscles during processing. In the dorsal muscle, no significant difference $(p>0.05)$ was found in the amount of carbonyl content between S-F and SS-F. However, carbonyl contents in S-F was higher than that in SS-F from 4 to 8 days of drying for the ventral muscle $(p<0.05)$, indicating that the His and/or Lys might inhibit the protein oxidation. The result was similar with the study by $\mathrm{Xu}^{65}{ }^{65}$ who found that Lys- or Argtreated sausages had significantly $(p<0.05)$ lower carbonyl values than the control during 10 to 25 day of storage. Many studies had revealed that positive correlation between protein oxidation and lipid oxidation. ${ }^{66,67}$ In the present study, a positive correlation between protein oxidation and lipid oxidation was also shown in Table 11, and the correlation coefficient between carbonyl contents and TBARS was $0.964(p<0.01)$. Amino acids with $\mathrm{NH}$ or $\mathrm{NH}_{2}$ moiety on their side chains can react with free oxygenated radical from lipolysis, then transforming into carbonyl groups. Carbonyl groups may be introduced into proteins by reactions with aldehydes (4-hydroxy-2-nonenal, malondialdehyde) produced during lipid peroxidation. ${ }^{68}$ In the previous study, Lys was reported to have metal chelating activity, ${ }^{69}$ indicating that Lys could prevent the oxidation of proteins. In our study, it was found that salt substitute inhibited the lipid oxidation due to the presence of histidine, which was a single oxygen scavenger. ${ }^{60}$

\section{Sulphydryl content}

Protein oxidation is also associated with a decrease in sulphydryl groups, which are converted into disulphide. ${ }^{70}$ The level of $\mathrm{SH}$ was shown in Fig. 1. There was a significant changes in $\mathrm{SH}$ content during processing $(p<0.05)$. In general, the $\mathrm{SH}$ content was decreased as processing time proceeding, which might correspond to the oxidation of accessible free thiol groups from cysteine residues located at the protein surface. ${ }^{71}$ There was a increase in $\mathrm{SH}$ content from end of salting days to 4 days both in the dorsal and
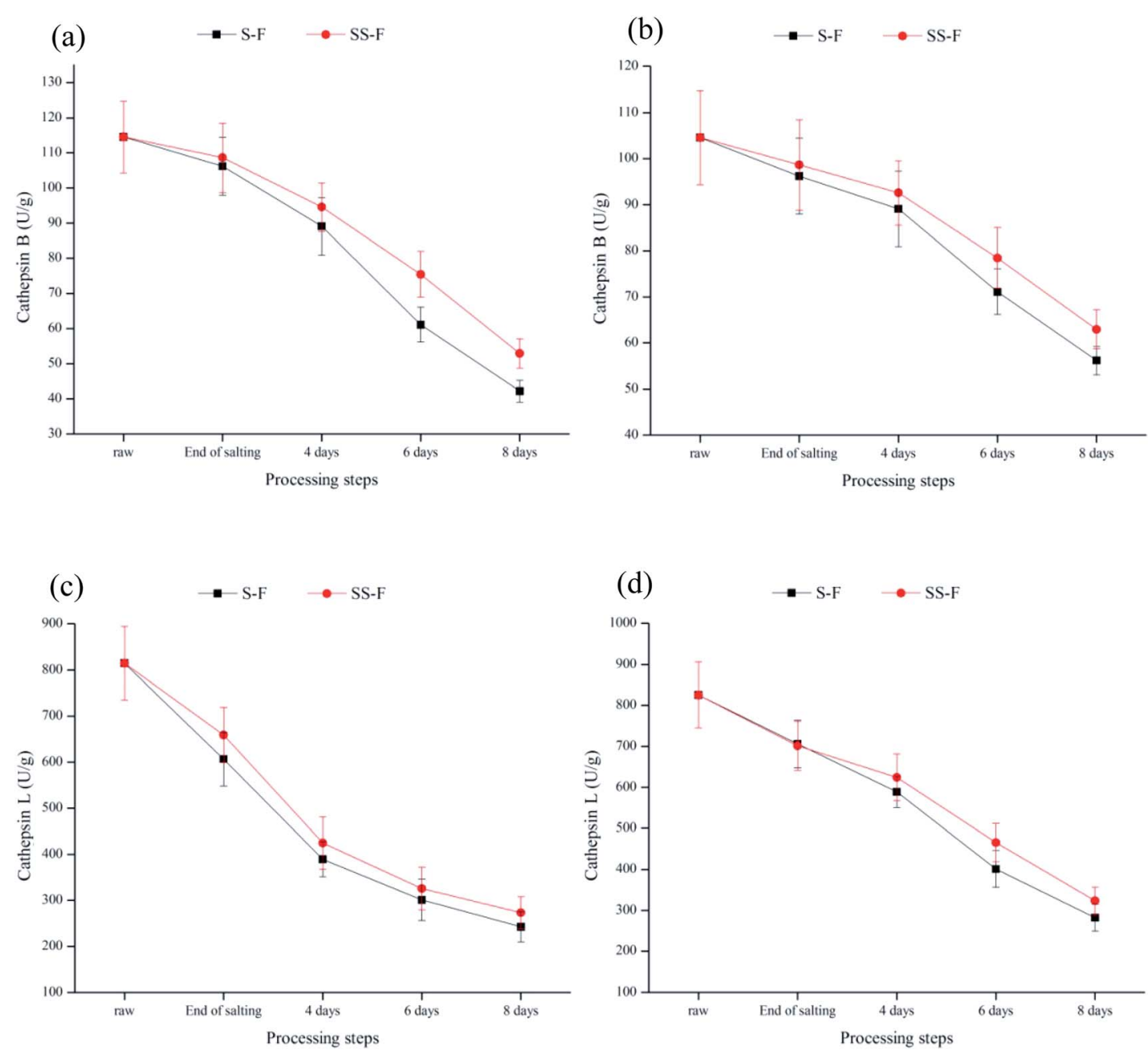

Fig. 2 Changes in relative activity of cathepsins B and L in dorsal ( $a$ and b) and ventral muscles (c and d) of salted fish with salt or SS treatments during processing. 


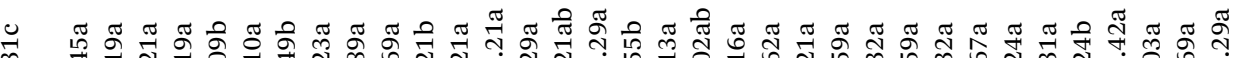

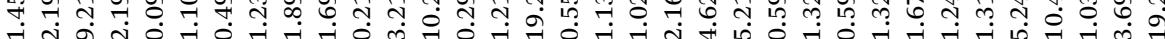
$H+H+H+H+H+H H+H+H+H+H+H+H+H+H+H+H+H+H+H+H+H+H+H$

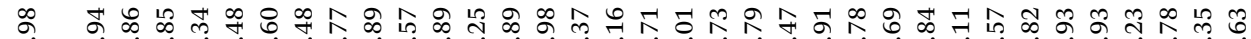

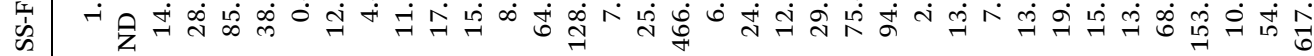

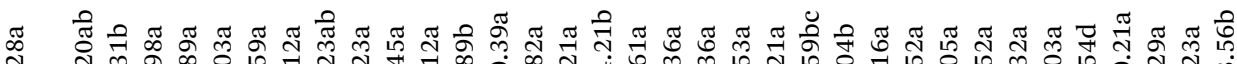
ণ্ড

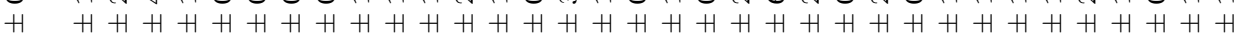

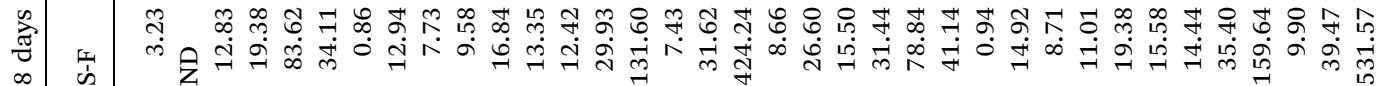

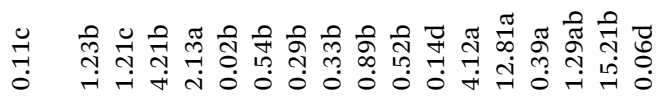
$H+H+H+H+H+H+H+H+H+H H H+H$

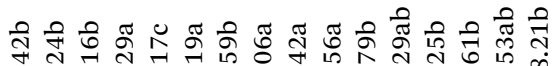

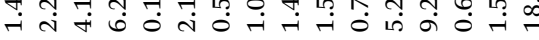
$H+H+H+H+H+H H H+H+H H+$

గొ

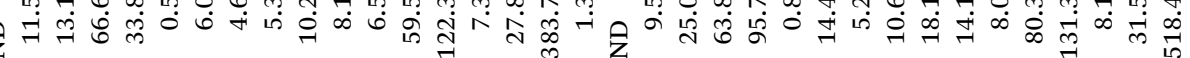

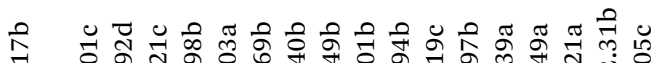
ने H H H H H H H H H H H H H H H H H H

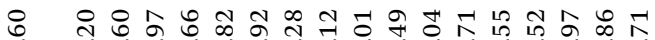

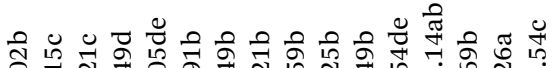

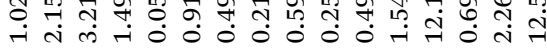
$H+H+H+H+H+H+H+H+H+H+H$

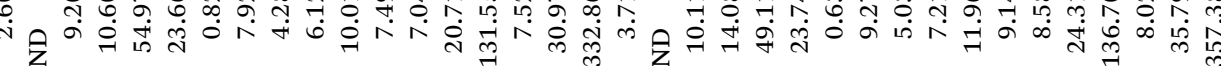

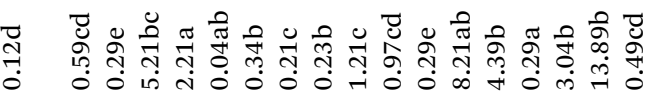
$H \quad H+H+H+H+H+H+H+H+H+H+H$

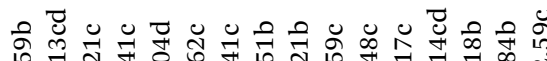

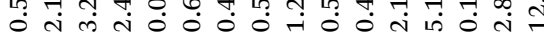
$H+H+H+H+H+H+H+H+H+H+H$

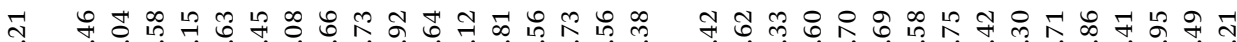

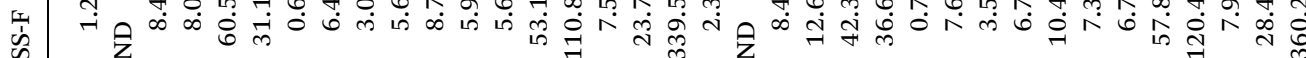

: ت 我 $H+H+H+H+H+H+H+H+H+H+H+H$

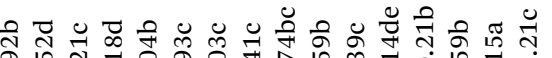

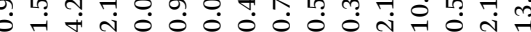

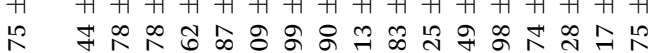
$H+H+H+H+H+H+H+H+H+H$

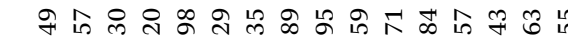
会

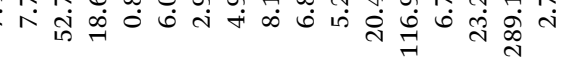

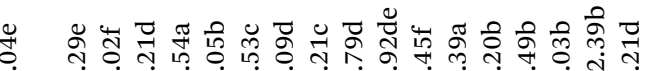

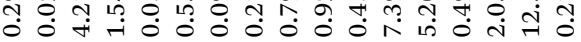
$H+H+H+H+H+H+H+H+H+H+H$ 我

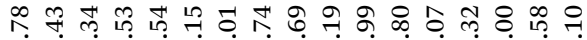

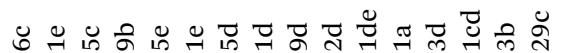

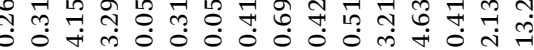
$H+H+H+H+H+H+H+H+H+H$

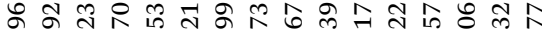

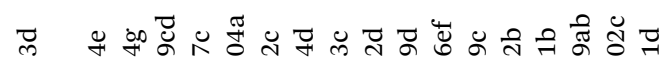

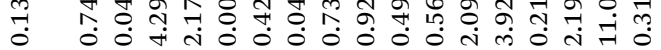
$H+H+H+H+H+H+H+H+H+H+H+H$

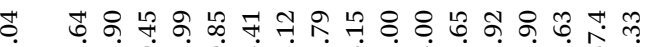

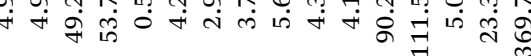

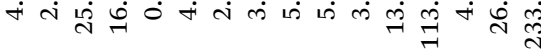

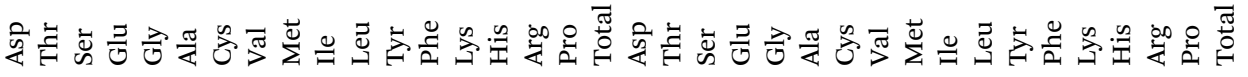



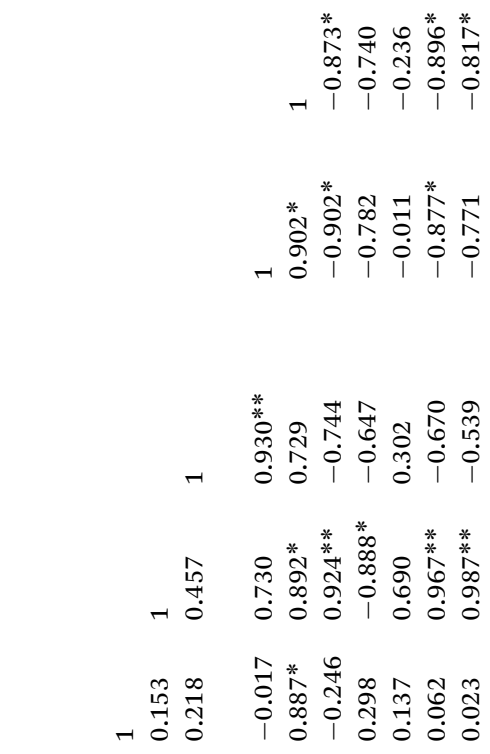

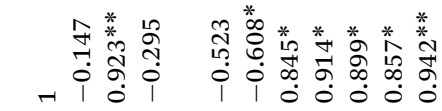

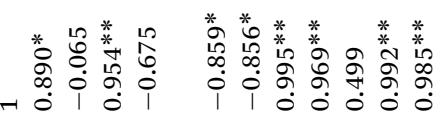

$$
\begin{aligned}
& \text { (1) }
\end{aligned}
$$

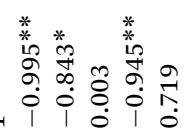

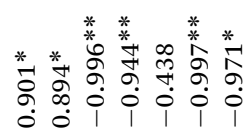

ventral muscle, due to the breakage of disulfide bond caused by proteolysis. In the dorsal muscle, compared with $\mathrm{SH}$ content in S-F, the SH content in SS-F decreased by $27.61 \%$, $11.01 \%$ and $13.77 \%$ from 4 days to 8 days, respectively. Meanwhile, it was decreased by $31.19 \%, 17.74 \%$ and $22.51 \%$ in the ventral muscle, respectively. The result indicated that the introduction of Lys and/or His increased the loss of free thiol groups. Zhang ${ }^{72}$ found that sage also accelerated the loss of thiol although it prevented protein oxidation. In $\mathrm{Xu}^{6} \mathrm{~s}^{65}$ study, he found that Lys treated sausages showed significantly lower $(p<0.05)$ thiol levels than those in the control during storage. $\mathrm{Liu}^{54}$ also reported that Lys and His increased the loss of thiol groups. In the presence of positively charged Lys and His, the $\alpha, \beta$-unsaturated compounds reacted with thiols, ultimately contributing to the decrease in thiol levels.

\section{Enzyme activities}

Cathepsins B and $\mathrm{L}$ were lysosomal proteinases played an important role in the proteolytic chain taking place during the curing process and affect the development of the sensory characteristics of meat products. ${ }^{73-76}$ The activities of cathepsins $B$ and $L$ were significantly decreased $(p<0.05)$ both in the dorsal and ventral muscles during processing (Fig. 2), which was primarily because of the inhibition effect of salt on their activities. $^{76}$ In the dorsal muscle, compared with S-F, cathepsin B activity in SS-F was increased by $2.30 \%, 6.13 \%, 23.47 \%$ and $25.50 \%$ from end of salting days to 8 days, respectively; while cathepsin L activity in SS-F was increased by $8.65 \%, 9.11 \%$, $8.08 \%$ and $12.70 \%$ from end of salting days to 8 days, respectively. Same tendency was observed in the ventral muscles. The results illustrated that salt substitute increased enzyme activity. Armenteros $^{77}$ found that $\mathrm{KCl}$ had a similar inhibition effect to $\mathrm{NaCl}$ for cathepsin $\mathrm{B}$ and $\mathrm{L}$. Therefore, the higher activity of cathepsin $\mathrm{B}$ and $\mathrm{L}$ was due to the replacement of $\mathrm{NaCl}$ by Lys and His.

\section{FAA content}

The FAA played an important role in the development of flavor. ${ }^{78}$ Therefore, it was important to determine their release in dry-cured fish. Changes of FAA content in dorsal and ventral muscles of salted fish treated with $\mathrm{NaCl}$ and salt substitute during processing were shown in Table 10. In the present study, the 17 FAA content at the end of processing was used as a measure of proteolytic activity. Statistical analysis displayed that total FAA was significantly $(P<0.05)$ increased throughout the whole manufacture process both in dorsal and ventral muscle, and the principal increase was in Gly, lys, Glu and Ala. This was in accordance with the previous studies. ${ }^{79-81}$ In addition, total FAA in SS-F was higher than that in S-F, which was increased by $15.40 \%, 17.43 \%, 15.28 \%$ and $9.88 \%$ in dorsal muscle, and $33.28 \%, 7.35 \%, 45.07 \%$ and $16.19 \%$ in ventral muscle, from end of salting to 8 days, respectively. In the dorsal muscle, at the end of processing, the content of Glu and Lys in SS-F was higher than that in S-F, while Cys, Met and Phe was found to be lower than that in S-F $(p<0.05)$. In the ventral 
muscle, the content of Ala, Cys and lys in SS-F was higher than hat in S-F, while Asp was found to be lower than that in S-F ( $p<$ 0.05). These results indicated that salt substitute increased the preteolysis, while total FAA content showed a positive correlation $(r=0.890, p<0.05)$ with cathepsin B activity (Table 11). Armenteros $^{77}$ found that the replacement of $\mathrm{NaCl}$ by $\mathrm{KCl}$ didn't cause significant changes in total FAA content. Hence, these results indicated that the introduction of His and/or Lys caused the release of FAA through proteolysis of proteins by endogenous enzymes and aminopeptidases activity. ${ }^{\mathbf{8 2} 83}$

\section{Conclusions}

In summary, salt substitute containing Lys and His accelerated the hydrolysis of protein and lipid and inhibit the oxidation of protein and lipid in dry-salted grass carp during processing. Salt substitute induced a marked reduction (>50\%) in the $\mathrm{Na}$ content and enhanced the phospholipase activity in dry-salted fish compared to the $\mathrm{NaCl}$ treated samples. Simultaneously, slightly higher lipolysis was observed in the fish samples treated with the salt substitute. In addition, the TBARS value, LOX activity and the value of conjugated diene were lower in the both muscles of SS-F group than S-F. The addition of Lys and His increased the activity of cathepsin B and L, leading to the increment of FAA content, while decreased the content of protein carbonyls and thiol groups. The use of salt substitute decreased the color, off-flavor and hardness of fish samples accompanied by the increase of aroma, without affecting overall acceptability of final products, indicating that $\mathrm{NaCl}$ could totally replaced by salt substitute containing Lys and His during the processing of the dry-salted grass carp. Therefore, it was suggested that the partial replacement of $\mathrm{NaCl}$ by Lys and His might be a possible approach to reduce the amount of sodium in dry-cured meat products, although its effect on the physicochemical and sensory properties of different dry-cured meat products remained to be further studied.

\section{Conflicts of interest}

The authors declare no conflict of interest.

\section{Acknowledgements}

Present work was supported by the National Natural Science Foundation of China (No. 31601491).

\section{References}

1 O. Martínez-Alvarez and M. C. Gómez-Guillén, Food Chem., 2006, 94, 123-129.

2 A. Fuentes, I. Fernández-Segovia, J. A. Serra and J. M. Barat, LWT-Food Sci. Technol., 2010, 43, 1433.

3 J. M. Barat, E. Pérez-Esteve, M. C. Aristoy and F. Toldrá, Plant Soil, 2013, 368, 179-188.

4 H. H. Hsu, T. C. Chuang, H. C. Lin, Y. R. Huang, C. M. Lin, H. F. Kung and Y. H. Tsai, Food Chem., 2009, 114, 933-938.
5 M. Armenteros, M. C. Aristoy, J. M. Barat and F. Toldrá, Meat Sci., 2012, 90, 361-367.

6 N. R. Cook, J. A. Cutler, E. Obarzanek, J. E. Buring, K. M. Rexrode, S. K. Kumanyika, L. J. Appel and P. K. Whelton, BMJ, 2007, 334, 885.

7 M. V. Nguyen, K. A. Thorarinsdottir, G. Thorkelsson, A. Gudmundsdottir and S. Arason, Food Chem., 2012, 131, 1322-1331.

8 B. Min and D. U. Ahn, Food Sci. Biotechnol., 2005, 14, 152153.

9 K. Lauritzsen, G. Martinsen and R. L. Olsen, J. Food Lipids, 1999, 6, 17.

10 M. Candek-Potokar and M. Skrlep, Animal, 2012, 6, 327-338.

11 M. Armenteros, M. C. Aristoy, J. M. Barat and F. Toldrá, Food Chem., 2009, 117, 627-633.

12 S. Ripollés, P. C. Campagnol, M. Armenteros, M. C. Aristoy and F. Toldrá, Meat Sci., 2011, 89, 58-64.

13 O. Martínez-Alvarez and M. C. Gómez-Guillén, Food Chem., 2005, 93, 125-133.

14 J. N. Park, K. T. Hwang, S. B. Kim and S. Z. Kim, Int. J. Food Sci. Technol., 2009, 44, 1572-1578.

15 R. Larsen and E. O. Elvevoll, Food Chem., 2008, 107, 369-376. 16 M. Aliño, R. Grau, D. Baigts and J. M. Barat, J. Food Eng., 2009, 95, 551-557.

17 M. W. Moody, G. J. Flick and R. E. Martin, The Seafood Industry, 2000, pp. 381-406.

18 M. Aliño, R. Grau, F. Toldrá, E. Blesa, M. J. Pagán and J. M. Barat, Meat Sci., 2010, 85, 580-588.

19 C. Zhou, J. Li and S. Tan, Food Sci. Biotechnol., 2014, 23, 775780.

20 R. Tahergorabi and J. Jaczynski, Food Chem., 2012, 132, 1281-1286.

21 R. Tahergorabi, S. K. Beamer, K. E. Matak and J. Jaczynski, LWT-Food Sci. Technol., 2012, 48, 175-181.

22 Y. W. Zhang, L. Zhang, T. Hui, X. Y. Guo and Z. Q. Peng, LWT-Food Sci. Technol., 2015, 64, 966-973.

23 J. Wasswa, J. Tang, X. H. Gu and X. Q. Yuan, Food Chem., 2007, 104, 1698-1704.

24 S. Testi, A. Bonaldo, P. P. Gatta and A. Badiani, Food Chem., 2006, 98, 104-111.

25 Y. W. Zhang, Q. L. Cheng, Y. Yao, X. Y. Guo, R. R. Wang and Z. Q. Peng, Eur. Food Res. Technol., 2014, 238, 565-571.

26 J. Folch, M. Lees and G. H. Sloane-Stanley, J. Biol. Chem., 1957, 226, 497-509.

27 B. W. Cui, Y. W. Zhang, F. L. Wang, M. A. Jamali and Z. Q. Peng, J. Anim. Sci., 2016, 94, 4427.

28 H. Stone and J. L. Sidel, Sensory evaluation practices, Elsevier Academic Press, California, 2nd edn, 2004, p. 377.

29 C. S. Vestergaard, C. Schivazappa and R. Virgili, Meat Sci., 2000, 55, 1-5.

30 F. Toldrá, M. Flores, M. Aristoy, R. Virgili and G. Parolari, J. Sci. Food Agric., 1996, 71, 124-128.

31 M. A. Kaluzny, L. A. Duncan, M. V. Merritt and D. E. Epps, J. Lipid Res., 1985, 26, 135-140.

32 W. R. Morrison and L. M. Smith, J. Lipid Res., 1964, 5, 600608. 
33 C. Coutron-Gambotti and G. Gandemer, Food Chem., 1999, 64, 95-101.

34 A. M. Salih, D. M. Smith, J. F. Price and L. E. Dawson, Poult. Sci., 1987, 66, 1483-1488.

35 V. Ollilainen, Meat Sci., 2009, 83, 104-112.

36 C. Cui, X. Zhou, M. Zhao and B. Yang, Innovative Food Sci. Emerging Technol., 2009, 10, 41.

37 J. M. A. Aro, P. Nyam-Osor, K. Tsuji, K. I. Shimada, M. Fukushima and M. Sekikawa, Food Chem., 2010, 119, 279-285.

38 M. McGuire and K. A. Beerman, Nutritional Sciences: From Fundamentals to Food, 3rd edn, 2012.

39 S. Testi, A. Bonaldo, P. P. Gatta and A. Badiani, Food Chem., 2006, 98, 104-111.

40 Y. W. Zhang, J. J. Wu, M. A. Jamali, X. Y. Guo and Z. Q. Peng, LWT-Food Sci. Technol., 2017, 85, 16-21.

41 D. A. Cristina, I. Seiquer and M. P. Navarro, J. Sci. Food Agric., 2004, 84, 1507-1513.

42 M. Aliño, R. Grau, F. Toldrá, E. Blesa and J. M. Barat, Meat Sci., 2009, 83, 423-430.

43 M. Aliño, R. Grau, F. Toldrá, E. Blesa, M. J. Pagán and J. M. Barat, Meat Sci., 2010, 85, 580-588.

44 K. Lauritzsen, L. Akse, A. Johansen, K. Lauritzsen, L. Akse, A. Johansen, S. Joensen, N. K. Sørensen and R. L. Olsen, Food Res. Int., 2004, 37, 677-688.

45 L. S. Stien, E. Hirmas, M. Bjørnevik, Ø. Karlsen, R. Nortvedt, A. M. B. Rørå, J. Sunde and A. Kiessling, Aquacult. Res., 2005, 36, 1197-1206.

46 C. Pérez-Santaescolástica, J. Carballo, E. Fulladosa, J. V. Garcia-Perez, J. Benedito and J. M. Lorenzo, Food Res. Int., 2018, 107, 559-566.

47 R. Virgili, G. Parolari, C. Schivazappa, C. S. Bordini and M. Borri, J. Food Sci., 1995, 60, 1183-1186.

48 P. C. B. Campagnol, B. A. D. Santos, M. A. Morgano and N. N. Terra, Meat Sci., 2011, 87, 239-243.

49 P. C. B. Campagnol, B. A. D. Santos, N. N. Terra and M. A. R. Pollonio, Meat Sci., 2012, 91, 334-338.

50 F. Toldrá, Dry-cured meat products, Food \& Nutrition Press, Trumbull, CT, 2002, pp. 1-238.

51 D. A. Los and N. Murata, Biochim. Biophys. Acta, Biomembr., 1998, 1394, 3-15.

52 P. A. Morrissey, P. J. A. Sheehy, K. Galvin, J. P. Kerry and D. J. Buckley, Meat Sci., 1998, 49, 73-86.

53 G. H. Zhou and G. M. Zhao, Meat Sci., 2007, 77, 114-120.

54 S. X. Liu, Y. W. Zhang, G. H. Zhou G, Y. J. Bao and Z. Q. Peng, Int. J. Food Prop., 2019, 22, 487-498.

55 M. Kaneniwa, S. Miao, C. Yuan, H. Lida and Y. Fukuda, J. Am. Oil Chem. Soc., 2000, 77, 825-831.

56 H. M. Verheij, J. J. Volwerk, E. H. J. M. Jansen, W. C. Puyk, B. W. Dijkstra, J. Drenth and G. H. de-Haas, Biochemistry, 1980, 19, 743-750.
57 F. P. Corongiu and S. Banni, Methods Enzymol., 1994, 233, 303-310.

58 H. H. F. Refsgaard, L. Tsai and E. R. Stadtman, Proc. Natl. Acad. Sci. U. S. A., 2000, 97, 611-616.

59 I. P. Ashton and H. A. Bremner, Safety and Quality Issues in Fish Processing, 2002, pp. 254-285.

60 X. Zhai, X. Zhou and M. Ashraf, J. Mol. Cell. Cardiol., 1995, 27, 2453-2464.

61 D. S. Robinson, Z. Wu, C. Domoney and R. Casey, Food Chem., 1995, 54, 33-43.

62 Y. Wang, Y. T. Jiang, Y. X. Cao, Y. J. Chen, Y. Y. Sun, X. Q. Zeng, D. D. Pang, C. R. Ou and N. Gan, Food Chem., 2016, 190, 33-40.

63 S. Banerjee, Food Res. Int., 2006, 39, 486-491.

64 S. K. Ling, T. Tanaka and I. Kouno, Biol. Pharm. Bull., 2003, 26, 352-356.

65 P. Xu, Y. Zheng, X. Zhu, S. Li and C. Zhou, Asian-Australas. J. Anim. Sci., 2018, 31, 905-913.

66 S. Ventanas, M. Estevez, J. F. Tejeda and J. Ruiz, Meat Sci., 2006, 72, 647-655.

67 E. Mario and C. Ramón, Meat Sci., 2004, 68, 551-558.

68 B. S. Berlett, J. Biol. Chem., 1997, 272(33), 20313-20316.

69 D. Campen and E. Gross, J. Nutr., 1969, 99, 68-74.

70 F. Batifoulier, Y. Mercier, P. Gatellier and M. Renerre, Meat Sci., 2002, 61, 389-395.

71 W. Sun, C. Cui, M. Zhao, Q. Zhao and B. Yang, Food Chem., 2011, 124, 336-341.

72 L. Zhang, Y. H. Lin, X. J. Leng, M. Huang and G. H. Zhou, Meat Sci., 2013, 95, 145-150.

73 I. F. Penny, Enzymology of conditioning, Developments in Meat Science, 1980.

74 D. J. Etherington, J. Anim. Sci., 1984, 59, 1644-1650.

75 F. Toldrá and M. Flores, Crit. Rev. Food Sci. Nutr., 1998, 38, 331-352.

76 E. Rico, F. Toldrá and J. Flores, Z. Lebensm.-Unters. Forsch., 1991, 193, 541-544.

77 M. Armenteros, M. C. Aristoy and F. Toldrá, Eur. Food Res. Technol., 2009, 229, 93-98.

78 R. Bermúdez, D. Franco, J. Carballo, M. Sentandreu and J. M. Lorenzo, Food Res. Int., 2014, 56, 226-235.

79 M. Armenteros, M. C. Aristoy, J. M. Barat and F. Toldrá, J. Agric. Food Chem., 2009, 57, 9699-9705.

80 J. J. Córdoba, T. Antequera, J. Ventanas, C. López-Bote, C. García and M. A. Asensio, Meat Sci., 1994, 37, 217-227.

81 F. Toldrá, M. C. Aristoy and F. Mónica, Food Res. Int., 2000, 33, 181-185.

82 M. J. Lorenzo and D. Franco, Meat Sci., 2012, 92, 704-714.

83 R. Virgili, G. Saccani, L. Gabba, E. Tanzi and C. S. Bordini, LWT-Food Sci. Technol., 2007, 40, 871-878. 